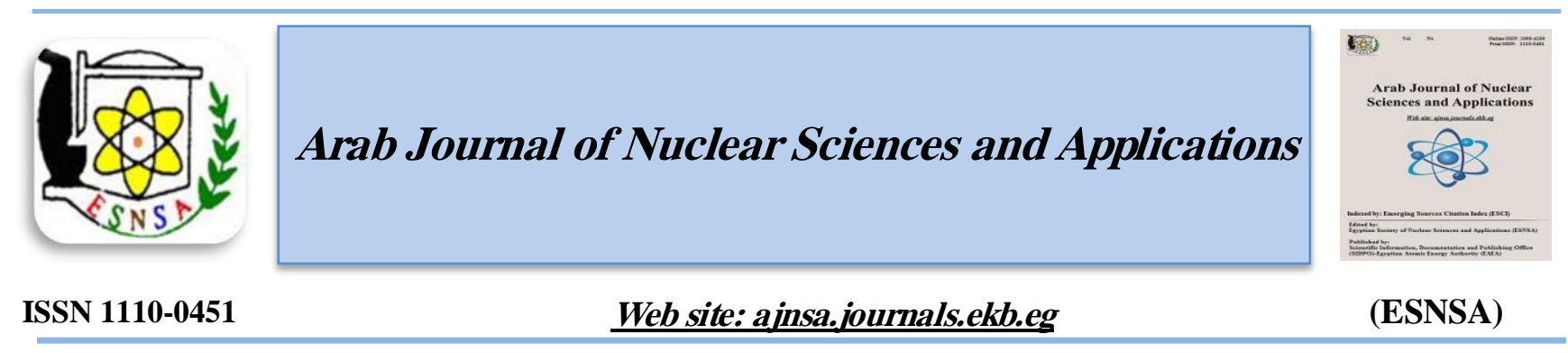

\title{
Modeling of Passive Safety Thermosyphon Loops Cooling System for Nuclear Applications
}

\author{
${ }^{\text {a} M . ~ A b d e l a z i z ~ S a l e m, ~}{ }^{b}$ Hesham Elkhatib, ${ }^{\text {a}}$ Mohamed A. Gaheen and ${ }^{\mathbf{c}}$ Said H. Zoalfakar \\ ${ }^{a}$ Department of Nuclear Safety Research and Radiological Emergencies - National Center for Radiation Research \\ and Technology, Atomic Energy Authority, Cairo, Egypt \\ ${ }^{b}$ Nuclear Reactors Department, Nuclear Research Center, Atomic Energy Authority, Cairo, Egypt \\ ${ }^{C}$ The Higher Technology Institute, $10^{\text {th }}$ of Ramadan City Egypt
}

Received $02^{\text {nd }}$ Apr 2018 Heat pipes are passive heat transfer devices, of long lives. Material and testing reactors (MTRs) have Accepted $17^{\text {th }}$ Apr 2019 residual heat after shutdown. Usually MTRs have also spent fuel storage tanks to compromise heat that need to be removed. Gravity assisted two-phase closed heat-pipe loop (GTPHL) covered by removal of decay heat (or heat after shutdown) with evaporator and condenser lengths each $100 \mathrm{~m}$ helical coil shape with outer diameter $15 \mathrm{~cm}$ and $3 \mathrm{~mm}$ thickness as a passive cooling system for a nuclear spent fuel storage pool. This study proposes a completely passive cooling system using thermosyphon loop for cooling and dissipation of the residual heat of wet spent fuel storage by running as main or alternative cooling system. The design focuses on heat removal from the spent fuel storage tank of a research reactor. The model considers natural convection by air for the condenser part of the heat-pipe loop to confine the residual heat. A numerical simulation, using special design of GTPHLs, was used to investigate the thermal performance of the GTPHL. The effects of heat loads were analyzed. Demineralized water was used as the GTPHL working fluid. The atmospheric air was circulated around the condenser as a cooling system. The thermal performance of the GTPHL is evaluated at heat input ranging from 25 to $150 \mathrm{~kW}$ with filling ratio of the working fluid of $100 \%$. The results show that a good thermal performance is obtained at high evaporator heat load obtained from nuclear spent fuel storage tank.

Keywords: Gravity assisted heat pipe, Passive Cooling System, Wet Spent Fuel Storage Heat Removal, Closed Two-Phase heat-pipe, Heat Pipe Simulation Model

\section{Introduction}

Safety features in nuclear reactors are the most important parameters that determine the possibility of public acceptance of these reactors. The term "nuclear" is usually perceived by the public as being associated with destruction or radioactive hazards on human health [1]. Nuclear safety regulations have been remarkably developed in the last decades. The risk of accidents in nuclear power plants is now becoming low and declining [6]. In over 16,000 cumulative reactor-years of commercial operation in 32 countries, there have been only three major accidents in nuclear power plants. These include Three Mile Island (USA 1979) where the reactor was severely damaged, but radiation was contained and there were no adverse health or environmental consequences, Chernobyl (Ukraine 1986) where the destruction of the reactor by steam explosion and fire killed 31 people and had significant health and environmental consequences. The death toll has since then increased to about 56. In the Fukushima accident

Corresponding author: bidosalem2@yahoo.com

DOI: 10.21608/ajnsa.2019.3357.1075

(C) Scientific Information, Documentation and Publishing Office (SIDPO)-EAEA 
(Japan 2011) where three old reactors (together with a fourth one) were written off and the effects of loss of cooling due to a huge tsunami were inadequately contained. Only the Chernobyl and Fukushima accidents resulted in radiation doses to the public greater than those resulting from the exposure to natural sources. Nuclear power plants are designed to be safe in their operation and in the event of any malfunction or accident, no industrial activity can be represented as entirely risk-free. Incidents and accidents may happen, and as in other industries, will lead to progressive improvement in safety. Current nuclear power reactors mainly use a combination of inherent safety characteristics, and engineered safety systems, whose function may be active or passive [2, 7, and 8]. The criticality accident at the Tokyo Electric Power Company's Fukushima Daiichi nuclear power plant in 2011, suggested reducing reliance on active systems so as to reduce human errors._However, the term passive safety is not a synonym for inherent safety, because the reactor remains subject to other kinds of failure such as structure or mechanical failure or human interference. This paper develops a model to evaluate the thermal performance of the GTPHL for application in nuclear reactors. Passive systems must fulfill some conditions. These conditions include reliability and availability in short and long terms under adverse conditions, longevity (shelf life) against corrosion or deformation, testability, and simplicity as well as other considerations for effective human-machine interaction. Grade (A) passive systems require no signal input, external power source, moving mechanical parts, nor moving working fluids. For example, nuclear fuel cladding, pressure boundary systems, hardened building structure against seismic and/or other external events are Grade (A) passive systems. For grade (B) passive systems, no signal input, no external power source, no moving mechanical parts, and moving working fluids are required. Examples of Grade (B) passive systems include natural air circulation around contaminant walls, reactor shutdown emergency cooling systems, and heat Pipe. For passive systems Grade (C), no signal input, or external power source are required, but moving mechanical parts, and moving or not working fluids are required. Examples of Grade (C) passive systems include cooling system based on fluid release through relief valves (accumulators). Grade (D) passive systems are called intermediate zone between active and passive processes, it needs external signal to trigger the passive process. It could be noticed that the more self-contained are the devices, the higher the degree of passivity is $[4,11]$.GTPHL consists of passive two-phase heat transfer devices that make use of the highly efficient thermal transport process of evaporator and condensation to maximize the thermal conductance between a heat source and a heat sink. The amount of heat that can be transferred by these devices is normally several orders of magnitude greater than pure conduction through a solid metal (exceeds that of copper 200500 times), [15, and 16]. GTPHL may be vertically oriented or inclined wickless heat pipe, with a liquid pool at the bottom. At operation, the GTPHL receives heat through the evaporator from an external source to the liquid pool. Consequently, a part of the working fluid evaporates. The vapor, driven by pressure differential between the evaporator and condenser flows through the adiabatic section towards the condenser section. In the condenser section, vapor is condensed into liquid imparting its latent heat of evaporation to the heat sink in the condenser section. The liquid returns internally from the condenser to the evaporator due to gravitational forces. Thus, the thermal-hydraulic cycle of the working fluid is completed.

\section{Theoretical Model \\ Equations}

A model describing both thermal and phase flows of the GTPHL has been performed by $\mathrm{M}$. Abdelaziz, et al [12] as shown in fig. 1. This model has been developed in order to provide numerical expressions of the variations in system variables, and, on the other hand, to give the expression of the GTPHL response time as a function of the various parameters. Such a model can also be used as a guide to the design of GTPHL. The first body represents the evaporator wall. It can be considered a thermally thin body represented by a temperature $\mathrm{T}_{\mathrm{w}}$. The second body is associated to the whole working fluid which exchanges with both evaporator wall and working fluid. The working fluid was considered saturated and has a temperature $T_{\mathrm{f}}$. This model presents a theoretical investigation of a wickless heat pipe or GTPHL behavior in transient regime. The transient model was adopted to simulate the response of the GTPHL. The transient thermal behavior of the 
GTPHL has been utilized in order to obtain a mathematical expression of the system response. A computer simulation program based on the method was developed to estimate temperature of the GTPHL as well as the time needed to reach steady state condition. The heat balance equations for each body (wall and fluid) give the following assumptions and equations:

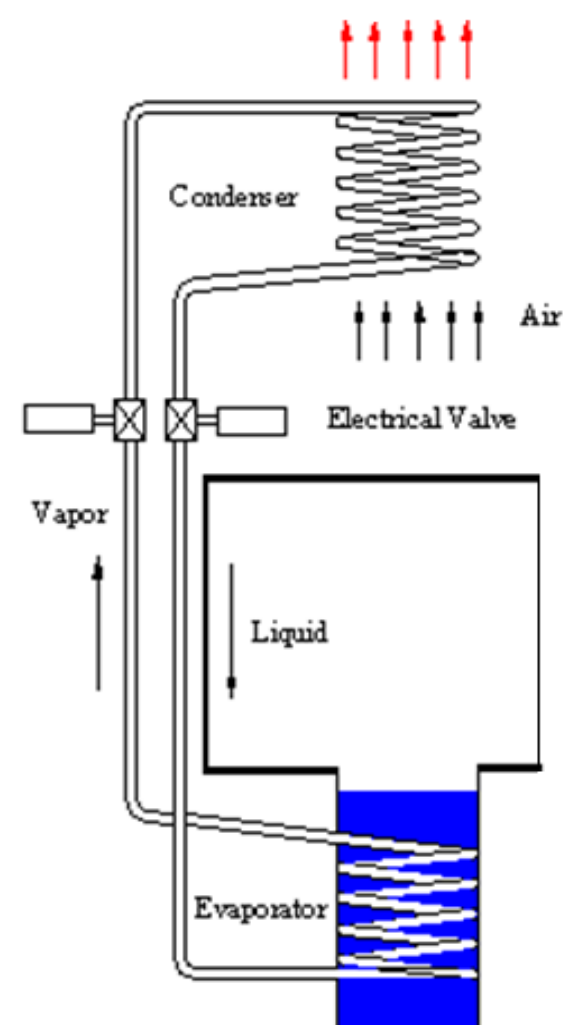

Fig. 1. Schematic diagram of the Proposed Passive Heat Pipe Loops Cooling System

\section{Assumptions}

1. A one-dimensional flow model.

2. GTPHL is in the vertical orientation.

3. The vapor superheat is very small; the vapor is taken at the saturated conditions.

4. Constant wall material (SS316) properties, such as density, specific heat and thermal conductivity.

5. The kinetic and potential energy components are neglected in the energy balance equations when compared with heat transfer rate.

6. The density, thermal conductivity, enthalpy and other properties of saturated liquid are temperature depended.

7. The local wall, working fluid and heat transfer coefficient of the evaporator and the condenser are calculated at mean value for both.

8. The heat-pipe starts up from initial condition when the power is suddenly on.

9. The heat-pipe steady-state carried out enough time.

$C_{w} \frac{\partial T_{w}}{\partial t}=Q_{s}-h_{e} \cdot S_{e} \cdot\left(T_{w}-T_{f}\right)$

$C_{f} \frac{\partial T_{f}}{\partial t}=h_{e}-h_{e} \cdot S_{e} \cdot\left(T_{w}-T_{f}\right)-h_{c} \cdot S_{c}\left(T_{f}-T_{w a t}\right)$

From equation 2-1 and by using the finite difference (Euler method) in certain time step $\Delta \mathrm{t}$, $\mathrm{T}_{\mathrm{w}}$. could be obtained

$T_{w}^{n+1}\left(C_{w}+h_{e} \cdot S_{e} \cdot \Delta t\right)-T_{f}^{n+1}\left(h_{e} \cdot S_{e} \cdot \Delta t\right)$

$=C_{w} \cdot T_{w}^{n}+\Delta t \cdot Q_{s}$

Using the average fluid temperature from equation (2-2) and by using the finite difference (Euler method) $\mathrm{T}_{\mathrm{f}}$ could be obtained

$$
\begin{aligned}
& T_{f}^{n+1}\left(C_{f}+\Delta t \cdot h_{e} \cdot S_{e}+\Delta t \cdot h_{C} \cdot S_{c}\right)-\Delta t \cdot h_{e} \cdot S_{e} \cdot T_{w}^{n} \\
& =C_{f} \cdot T_{f}^{n}+\Delta t \cdot h_{c} \cdot S_{c} \cdot T_{w a t}
\end{aligned}
$$

Where:

$\mathrm{T}_{\mathrm{w}}$ : is the average evaporator wall temperature.

$\mathrm{T}_{\mathrm{f}}$ : is the average fluid temperature.

$\mathrm{S}_{\mathrm{e}}$ : is the inner surface of the evaporator $=$ $\pi^{*} \mathrm{D}^{*} \mathrm{~L}_{\mathrm{evap}}$

$\mathrm{S}_{\mathrm{c}}$ : is the outer surface of the condenser $=$ $\pi^{*} \mathrm{D}^{*} \mathrm{~L}_{\mathrm{cond}}$

$\mathrm{C}_{\mathrm{f}}$ : is the thermal capacitance of the working fluid.

$\mathrm{C}_{\mathrm{w}}$ : is the thermal capacitance of the heatpipe wall.

$h_{e}:$ is the average evaporator heat transfer coefficient.

$\mathrm{h}_{\mathrm{c}}:$ is the average condenser heat transfer coefficient.

Radial heat flux, qr in evaporator is given as:

$\mathrm{q}_{\mathrm{r}}=\mathrm{Q}_{\text {net }} / \mathrm{A}_{\mathrm{r}}=$ Qnet $/\left(\pi * \mathrm{~d}_{\mathrm{i}}^{*}\right.$ Le $)$

Axial heat flux $\mathrm{q}_{\mathrm{ax}}$ of thermosyphon is given as:

$\mathrm{q}_{\mathrm{ax}}=\mathrm{Q}_{\mathrm{net}} / \mathrm{A}_{\mathrm{c} . \mathrm{s}}=\mathrm{Q}_{\mathrm{net}} /\left(\pi * \mathrm{~d}_{\mathrm{i}}^{2} / 4\right)$

Evaporator average heat transfer coefficient

Arab J. Nucl. Sci. \& Applic. Vol. 52, No.3 (2019) 
From equation (2-8) the process of heat transfer in the liquid pool of the evaporator section is generally assumed to be common nucleate boiling whose heat transfer coefficient may be calculated from Forester-Zuber equation [13, 17, 18, and 19], as:

$h_{e}=\frac{0.00122 \cdot \Delta \mathrm{T}_{\text {sat }}{ }^{0.24} \cdot \Delta \mathrm{P}_{\text {sat }}{ }^{0.75} \cdot \mathrm{cp}^{0.45} \cdot \rho^{0.49} \cdot \mathrm{k}^{0.79}}{\sigma^{0.5} \cdot \mathrm{h}_{\mathrm{fg}}{ }^{0.24} \cdot \mu_{\mathrm{L}}{ }^{0.29} \cdot \mathrm{pg}^{0.24}}$

$\Delta \mathrm{T}_{\text {sat }}$ is working fluid saturation temperature; $\Delta \mathrm{P}_{\text {sat }}$ is working fluid saturation pressure;

$\mathrm{Cp}_{1}$ is working fluid specific heat at constant pressure;

$\mathrm{K}_{1}$ is working fluid thermal conductivity;

$\rho_{1}$ is working fluid density;

$\rho_{\mathrm{g}}$ is vapor density.

\section{Condenser average heat transfer coefficient}

Natural convection heat transfer on a surface depends on the geometry of the surface and on its orientation. It also depends on the variation of temperature on the surface and the thermo-physical properties of the fluid involved [14]. Heat transfer relations in some cases of natural convection are based on experimental studies of numerous correlations of varying complexity and claimed accuracy available in the literature for any given geometry. The best known and widely used ones are used in the current study. The empirical correlations for the average Nusselt number, $\mathrm{Nu}$, in natural convection are of the form:

$$
G r_{L}=\frac{g . \beta \cdot\left(T_{s}-T_{\infty}\right) L_{c}^{3}}{\gamma^{2}}
$$

The characteristic length of the pipe is its diameter D.

$$
N u=\frac{h . . D}{k}=C\left(G r_{D} \cdot \operatorname{Pr}\right)^{n}=C \cdot R a ._{D}^{n}
$$

The values of the constants $C$ and $n$ depend on the geometry of the surface and the flow regime, which is characterized by the range of the Rayleigh number. The value of $n$ is usually $1 / 4$ for laminar flow and $1 / 3$ for turbulent flow. The value of the constant $\mathrm{C}$ is normally less than (1) Where $\mathrm{Ra}_{\mathbf{D}}$ is the Rayleigh number, which is the product of the Grashof and Prandtl numbers:

$$
R a_{D}=G r_{L} \operatorname{Pr}=\frac{g \cdot \beta \cdot\left(T_{s}-T_{\infty}\right)}{\gamma^{2}} p r
$$

The empirical correlation for the average Nusselt number for natural convection over horizontal cylinder is expressed as:

$$
N u=\left[0.6+\frac{0.387 R a_{D}{ }^{1 / 6}}{\left[1+(0.559 / \mathrm{Pr})^{9 / 16}\right]^{8 / 27}}\right]^{2}
$$

Where Nusselt number is used to calculate convective heat transfer coefficient as follows:

$$
N u=\frac{h \cdot D}{k}
$$

When the average Nusselt number and thus the average convection coefficient is known, the rate of heat transfer by natural convection from a solid surface at a uniform temperature, $T_{s}$ to the surrounding fluid is expressed by Newton's law of cooling.

Where $A_{s}$ is the heat transfer surface area and $h$ is the average heat transfer coefficient on the surface.

$$
\begin{aligned}
& Q_{\text {conv }}=h A_{s}\left(T_{s}-T_{\infty}\right) \\
& A_{s}=\pi \cdot D \cdot L \\
& U=\left(\frac{1}{h_{i}}+\frac{t}{k_{p}}+\frac{1}{h_{o}}\right)^{(-1)} \\
& \boldsymbol{\beta}=\frac{\mathbf{1}}{\boldsymbol{T}}
\end{aligned}
$$

T: Fluid temperature.

$\beta$ : Coefficient of expansion

\section{Model description}

A computer mathematical model was developed to calculate the temperature of the GTPHL as well as the time needed to reach steady state conditions. The equations are solved by Engineering Equation Solver program (EES)[15]. The program comprises three main sections. The first section contains the initial conditions such as the ambient temperature, basic gravity assisted heat-pipe loop dimensions, material and configuration, cooling water temperature and cooling water flow rate. As input data, these parameters are combined to calculate the physical properties of the working fluid and heat-pipe for each section. The second section of the program covers the transient calculation of the two-phase..... (considering the saturation temperature of the fluid). In this section, the mean wall, condenser fluid, and cooling flow rate temperatures for start-up and steady state process is calculated. In the third section of the 
program, a replacement of the initial conditions is achieved by the new calculated data. The program progresses until a steady-state is reached at different heat loads as illustrated in Table (1).

Table (1) Model heat load ranges

\begin{tabular}{|c|c|c|c|c|c|c|}
\hline $\begin{array}{c}\text { Heat- } \\
\text { pipe } \\
\text { diameter. } \\
(\mathrm{cm})\end{array}$ & $\begin{array}{c}\text { Condenser } \\
\text { Lenth L } \\
\text { (m) }\end{array}$ & $\begin{array}{c}\text { Filing } \\
\text { ratio } \\
\%\end{array}$ & $\begin{array}{c}\text { Ambient } \\
\text { Temp. } \\
{ }^{\circ} \mathrm{C}\end{array}$ & $\begin{array}{c}\text { Nuclear } \\
\text { Heat } \\
\text { Load Q } \\
\text { Range } \\
(\mathrm{KW})\end{array}$ & $\begin{array}{c}\text { Studied } \\
\text { Parameter }\end{array}$ & Material \\
\hline 15 & 100 & $100 \%$ & 30 & $\begin{array}{c}25-50- \\
75-100- \\
125-150\end{array}$ & Heat load & St.St.316 \\
\hline
\end{tabular}

\section{Results}

\section{Transient analysis}

Transient analysis is performed at start-up and steady-state for GTPHL for nuclear wet fuel storage tank using water as a working fluid. These predictions involve the change of wall and fluid temperatures during the startup transient. In this model, the heat-pipeloop is initially $(\mathrm{t}=0 \mathrm{~s})$ at the ambient temperature, then the power input to the evaporator is realized. The program runs for each interval of time $\Delta t$, till the heat-pipeloop temperature reaches the steady state. Figure 2(a) shows the average heat-pipe wall and the working fluid temperatures versus time. In the proposed model, for the heat-pipe loop water was used as a working fluid, the time required to reach the steady state condition is about 2500 seconds. Figure 3(a and b)shows the increment of average wall and fluid temperatures with time because the vapor density is too low to support continuum flow and the heat added to the heat-pipe loop evaporator is absorbed solely as sensible heating, resulting in a temperature rise. As a result, the temperature gradient of evaporator section is considered relatively high in the first interval of heating $(\mathrm{t}=0$ $2500 \mathrm{sec}$.). While the rest of the heat energy forms some vapor, which flows from the evaporator and condenses on the beginning section of the condenser section causing its surface temperature to rise. In this period of time, the response of the condenser section is lower than the evaporator section. At the time range $t>2500 \mathrm{sec}$. most of the heat energy is absorbed as latent heat in the working fluid, thus increasing the generated vapor. The vapor temperature is high enough to sustain continuum flow. Finally, as the steady state is approached, the rate of temperature increase slows down. This is due to the decrease in temperature difference between the vapor and the working fluid.

\section{Discussion}

Average evaporator wall and fluid temperatures, evaporator and condenser heat transfer coefficients, the output power from condenser section and temperature difference between evaporator and condenser are discussed. At a certain value of thermal load, Fig. 3(a and b) illustrates the mean temperatures predicted by the mathematical model for average evaporator wall, fluid and condenser wall temperatures (equations (2-3), (2-4)). As a result of increasing of the input power, the rate of change temperature with time increased. The intensity of heat transfers within the heat-pipe loop is analyzed through the determination of the average heat transfer coefficients $h_{e}$ and $h_{c}$ in the evaporator and condenser. The average heat transfer coefficients $\mathrm{h}_{\mathrm{e}}$ is estimated for the start-up and steady-state conditions by means of the mathematical model / equation (2-8) are calculated for different thermophysical properties of the working fluid including two subsequent processes, heat-up transient and steady-state as shown in Figs. 3(c and d). The estimation is carried out in the case of different heat loads ranged from 25 to $150 \mathrm{~kW}$ and high values of filling ratio of $100 \%$ (i.e. the evaporator is fully filled with liquid).At the condenser section, a global heat transfer coefficient $h_{c}$ has been considered which combines conduction through the wall and convection (external side of the wallair, the cooling section).Figs. 3(c, d and e) based on equation 2-14, shows that there little changes at the overall condenser heat transfer coefficient during all processes of the operation for the two processes, heat-up transient and steady-state. Figure 3(c and d) shows an increase in the heat transfer coefficient with increasing the heat load. Also, the output power from condenser section respectively versus time. The heat-pipe loop is initially at the room temperature, and then the power input to the evaporator is increased in a step from zero to the full power. The results reveal that the temperatures of each section and the output power increase rapidly at the beginning of operation due to the increase of heat flow from an object to another, with time. However, as a result of reduction of the temperature driving forces, the rate of changing temperature with time decreases until steady state condition is reached. At the steady-state, the wall and fluid temperatures, heatpipe evaporator and condenser sections and the output-power remain constant. The model is 
developed to simulate the full transient operation of heat-pipe loop and the entire heat-pipe loop feature including heat-pipe resistance. This means that there are variations between the average outer wall temperature of the evaporator and that of the condenser $\left(T_{w}-T_{f}\right)$, Figure 3(f) illustrates temperature variations during heat-up transient and steady-state.

Pool Temperature decrease at different heat loads The effect of the heat load when sudden heat generation is stopped was investigated for heat loads ranging from $25 \mathrm{~kW}$ to $150 \mathrm{~kW}$. Figure (4) shows the temperature gradient decay along the time inside the reactor fuel storage tank. From this figure, it can be noticed that the fuel storage pool temperature predictions decreased along approximately ten hours. It is clear that the temperature distributions tend to have different trends depending on the studied heat-pipe loop heat loads. For the storage pool which has the heatpipe loop evaporator, the lowest temperature distribution occurs at $25 \mathrm{~kW}$ and the highest temperature distribution decay occurs at $150 \mathrm{~kW}$. The cooling process is conducted according to Lumped Capacitance Method, it is assumed that the water in the pool is at temperature $T_{i}$, and is cooled naturally to lower temperature $\mathrm{T}_{\infty}$. This reduction is due to convection heat transfer at the solid-liquid interface. The essence of the lumped capacitance method is the assumption that the temperature of the solid is spatially uniform at any instant during the transient process. The heat equation is a differential equation governing the spatial temperature distribution due to transient decay. Instead, the transient temperature response is determined by formulating an overall energy balance on the heat pipe condenser evaporator portion. This balance must relate the rate of heat loss at the surface to the rate of change of the internal energy in the storage pool. In this case, the conservation requirement becomes:

$E_{\text {in }}-E_{\text {out }}=0$

$\mathrm{E}_{\text {in }}$ is inlet Energy;

$E_{\text {out }}$ is outlet energy

Even though energy generation may occur in the medium, the process would not affect the energy balance at the control surface. Moreover, this conservation requirement holds for both steadystate and transient conditions. Three heat transfer terms are shown for the control surface. On a unit area basis, they are conduction from the medium to the control surface convection from the surface to a fluid and net radiation exchange from the surface to the surroundings. The energy balance then takes the form.

$q_{\text {cond }}-q_{\text {conv }}-q_{\text {rad }}=0$

The radiation term is neglected, so the equation is reduced after arrangement to:

$$
\rho \cdot V \cdot \frac{d T}{d T}=U \cdot A \cdot\left(T-T_{\infty}\right)
$$

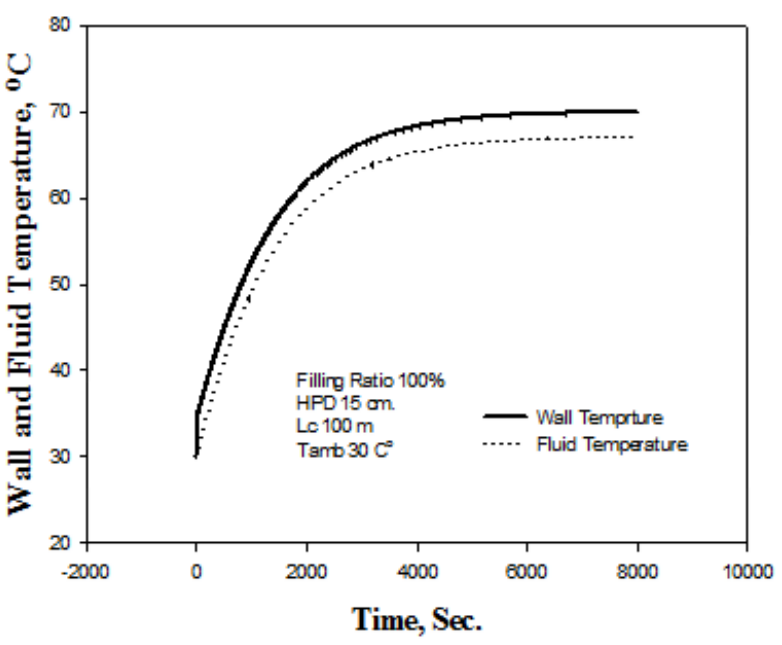

(a)

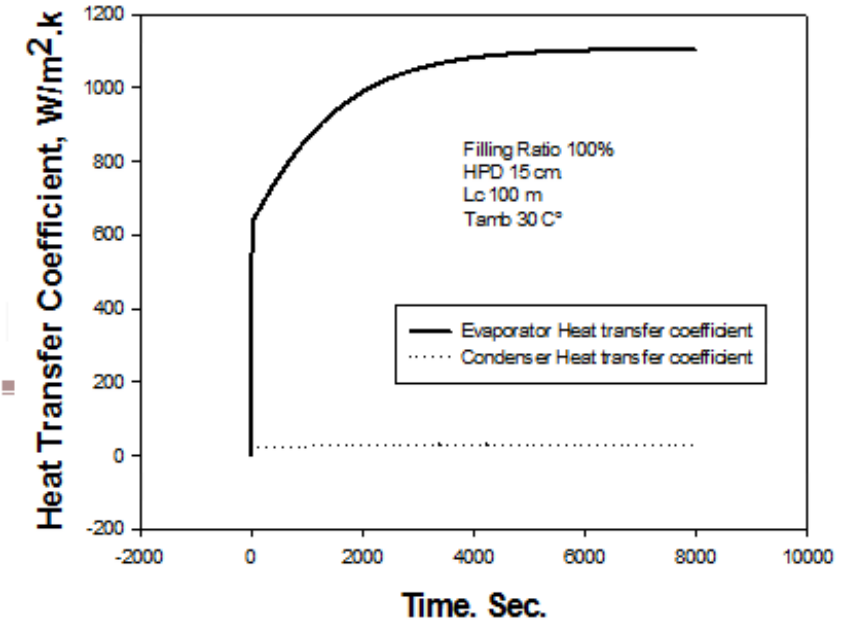

(b)

Fig. 2. Effect of different heat pipe parameters at different heat loads: (a) Wall and Fluid Temperature at 150Kw,(b) Average evaporator and condenser heat transfer coefficient of heat-pipe at $150 \mathrm{~kW}$ heat loads, 


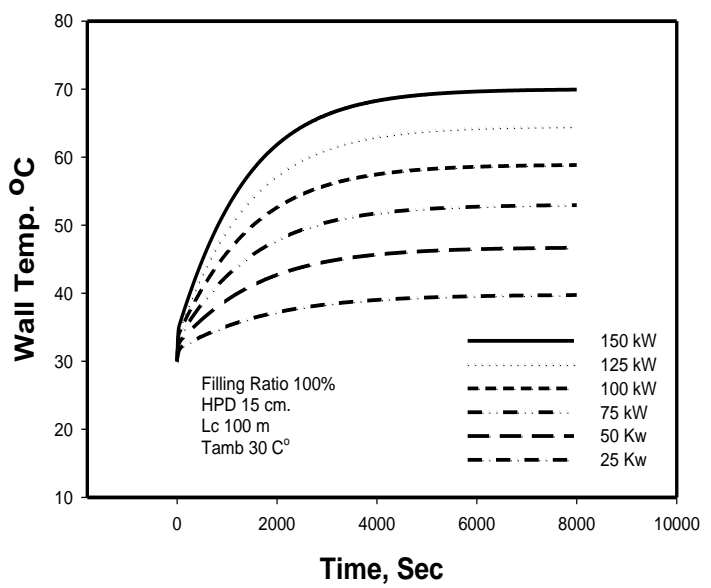

(a)

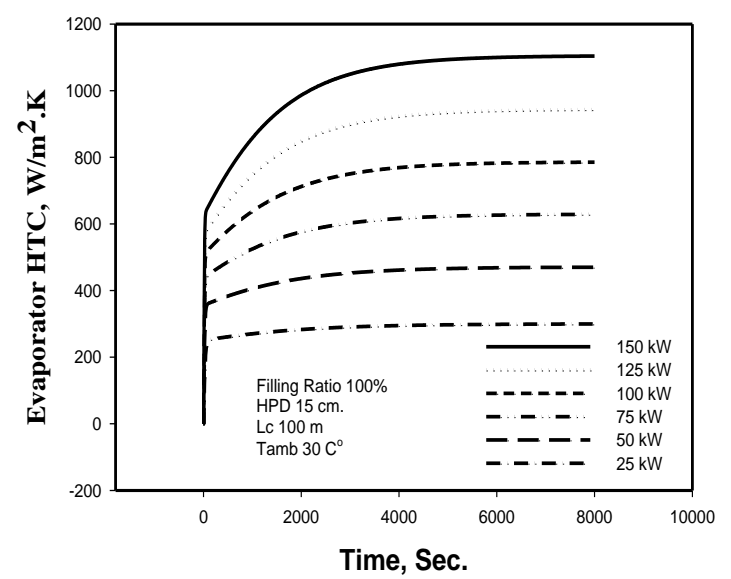

(c)

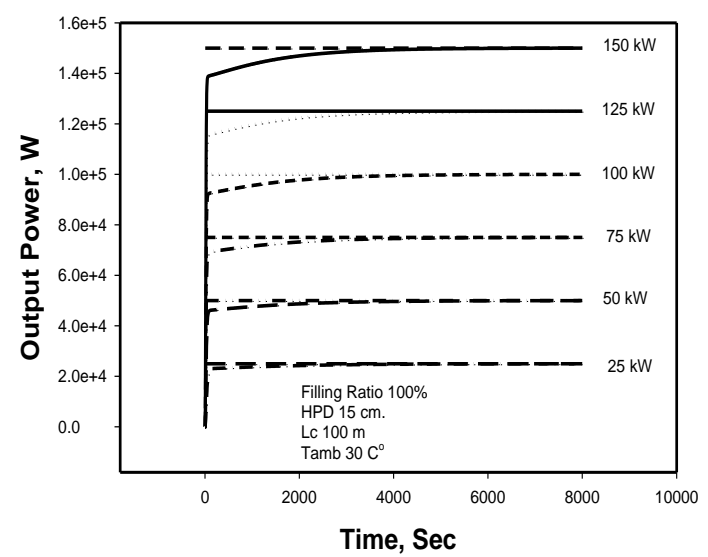

(e)

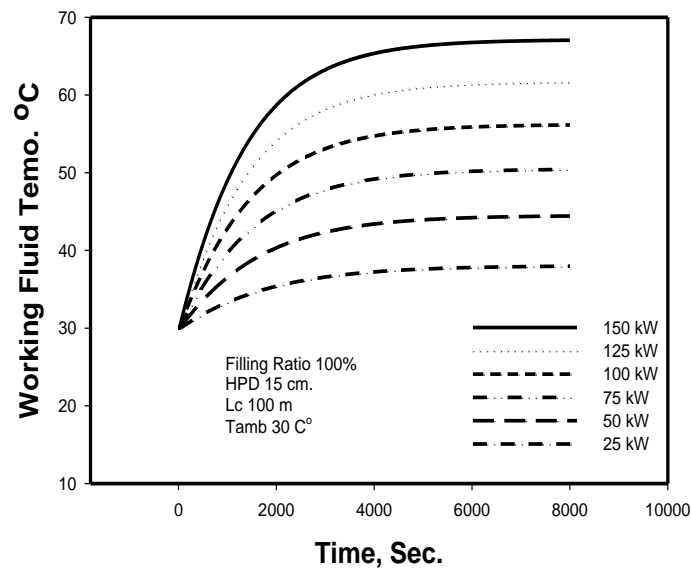

(b)

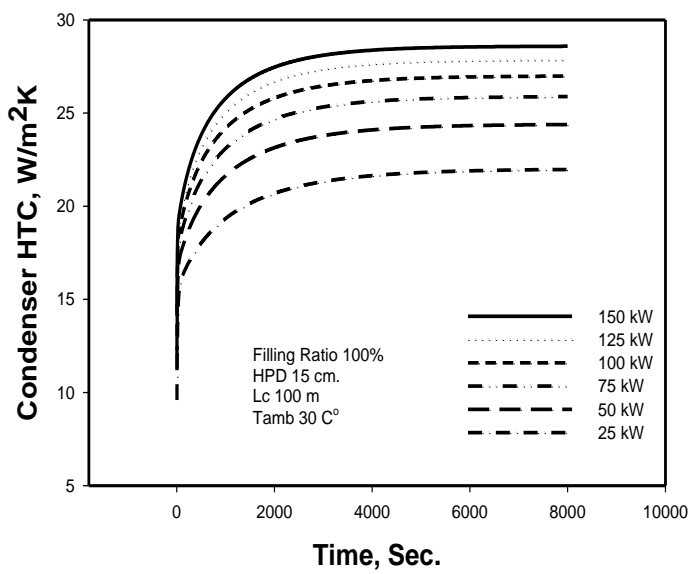

(d)

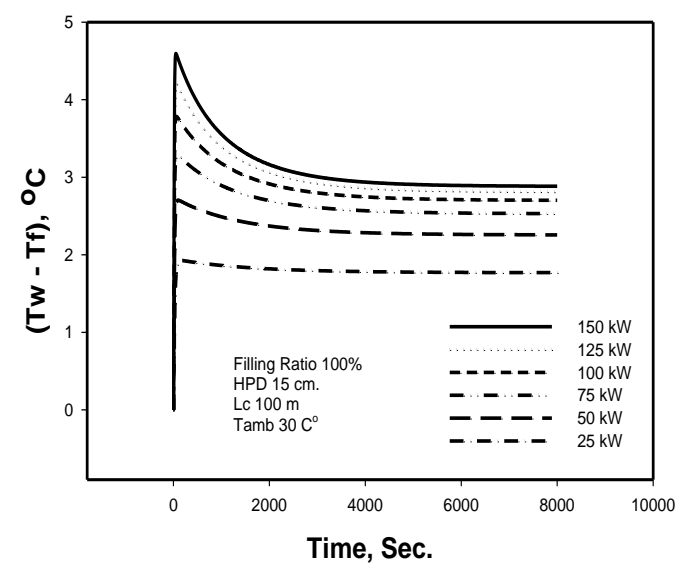

(f)

Fig. 3. Effect of different heat pipe parameters at different heat loads: (a) Wall Temperature of heat-pipe, (b)Fluid Temperature of heat-pipe, (c) average evaporator heat transfer coefficient of heat-pipe, (d) average condenser heat transfer coefficient of heat-pipe, (e) Output power of heat-pipe, (f) Temperature difference between wall and fluid temperature 


\section{Conclusion}

A numerical simulation using special design of St. St. 316 gravity assisted two-phase closed heat-pipe loops were used to evaluate the GTPHL thermal performance. The effect of the evaporator and condenser configuration, atmospheric air temperature, and heat load were analyzed. Demineralized water was used as the GTPHL's working fluid. The atmospheric air was circulated around the condenser as a cooling system. The results show that the best thermal performance was obtained at high evaporator heat load. The simulation model showed a pattern and trend line that can be used to predict the heat transfer phenomena of the GTPHL with varying inputs.

A theoretical network model has been proposed to predict the transient response of a gravity-assisted two-phase heat pipe working with pure water at different heat loads of $25,50,75,100,125$ and 150
$\mathrm{kW}$. The wall and fluid temperatures, heat transfer coefficients, time constants, and other thermal characteristics have been estimated and the following conclusions can be drawn:

1. The transient response of a gravity-assisted heat pipe is found to depend mainly on the evaporator heat load. Increasing the heat loads causes a reduction in the time constants, which leads to a better performance of the heat pipe.

2. The evaporator and condenser heat transfer coefficients are found to increase with power increase, though the corresponding values of the later are much less than those obtained for the evaporator.

3. The time needed for the spent fuel storage tank temperature to go down to ambient temperature is about $10 \mathrm{hrs}$.

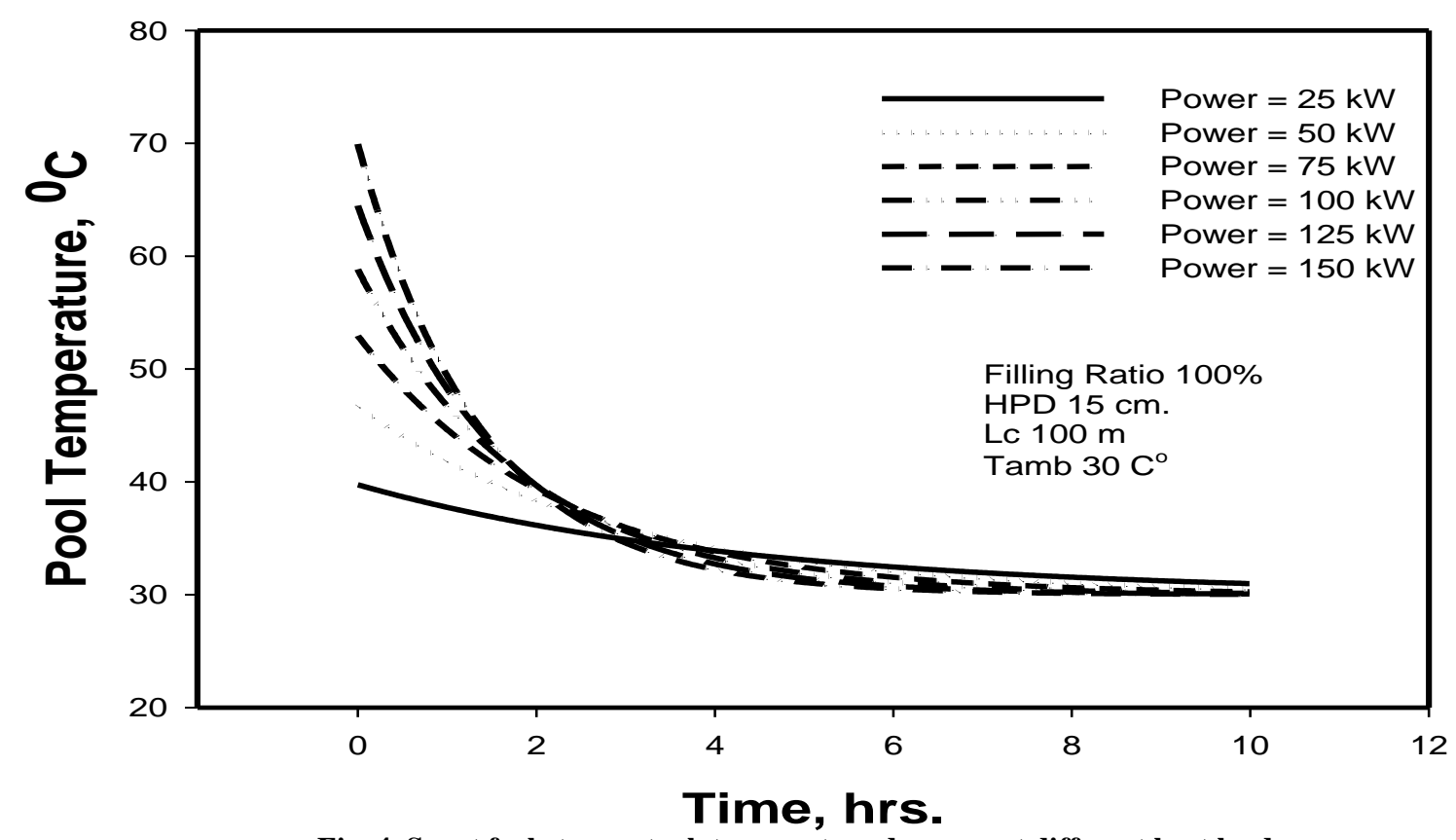

Fig. 4. Spent fuel storage tank temperature decrease at different heat loads

\section{Nomenclature}

S: area $(\mathrm{m} 2)$

cp: specific heat $(\mathrm{J} / \mathrm{kg}$. K)

g: gravity $\left(9.81 \mathrm{~m} / \mathrm{s}^{2}\right)$

$\mathbf{h}_{\mathbf{f g}}$ : latent heat of vaporization $(\mathrm{J} / \mathrm{kg} . \mathrm{K})$,

p: pressure $\left(\mathrm{N} / \mathrm{m}^{2}\right)$

t: time (s)

HTC: Heat transfer coefficient

Greek Symbols:

$\boldsymbol{\mu}$ : Dynamic viscosity (N.s/m2)

$\mathbf{v}$ : kinematics viscosity ( $\mathrm{m} 2 / \mathrm{s})$
$\mathbf{A}_{\mathrm{c}}$ : cross section area $(\mathrm{m} 2)$,

d: diameter (m),

h: heat transfer coefficient $\left(\mathrm{W} / \mathrm{m}^{2} . \mathrm{K}\right)$

$\mathbf{K}$ : thermal conductivity (W/m.K)

$\mathbf{q}:$ Heat flux $\left(\mathrm{W} / \mathrm{m}^{2}\right)$

T: temperature $\left({ }^{\mathrm{O}} \mathrm{C}\right)$

$\boldsymbol{\rho}$ : density $(\mathrm{kg} / \mathrm{m} 3)$,

$\tau$ : time constant (s) Abbreviations 


\author{
$\mathbf{G r}_{\mathrm{L}:}$ Grashof number \\ Nu: Nusselt number \\ Cp : specific heat of liquid (kJ/kg.K) \\ Ra: Rayleigh number \\ g: Gravitational acceleration \\ $\mathbf{T}_{\mathbf{s}}$ : Temperature of the surface \\ $\mathbf{L}_{\mathbf{c}}$ : Characteristic length of the geometry \\ Subscripts: \\ am: ambient \\ e : evaporator \\ eq: equivalent \\ m: mean \\ c: condenser \\ v: vapor
}

\section{References}

1.Basic Safety Principles for Nuclear Power Plants 75INSAG-3 Rev. 1 INSAG-12 A REPORT BY THE INTERNATIONAL NUCLEAR SAFETY ADVISORY GROUP

2.Root Causes and Impacts of Severe Accidents at Large Nuclear Power Plants. Luthagsesplanaden Uppsala, Sweden Luthagsesplanaden 14, 75225 Uppsala, Sweden Lars Högberg, 2013 Apr; 42(3): 267-284.

3.Fukushima Nuclear Accident Analysis Report. June 20, 2012 Tokyo Electric Power Company, Inc.

4.Technical feasibility and reliability of passive safety systems for nuclear power plants. Proceedings of an Advisory Group meeting held in Julich, Germany, 21-24 November 1994.

5.S. H. Noie, "Heat transfer characteristics of a twophase closed thermosyphon" Applied Thermal Engineering, Vol. 25, 2005, pp. 495-506.

6.C. Ye, M.G. Zheng, M.L. Wang, R.H. Zhang, Z.Q. Xiong, The design and simulation of a new spent fuel pool passive cooling system, Ann. Nucl. Energy 58 (2013) 124 to 131.

7.B.S. Jackel, Status of the spent fuel in the reactor buildings of $€$ Fukushima Daiichi 1e4, Nucl. Eng. Des. 283 (2015) 2 to 7.

8.V. Ognerubov, A. Kaliatka, V. Vileiniskis, Features of modeling of processes in spent fuel pools using various system codes, Ann. Nucl. Energy 72 (2014) 497 to 506.

9.X. Wu, W. Li, Y. Zhang, W. Tian, G. Su, S. Qiu, Analysis of the loss of pool cooling accident in a PWR spent fuel pool with MAAP5, Ann. Nucl. Energy 72 (2014) 198 to 213.

10.V.L. Sailor, K.R. Perkins, J.R. Weeks, H.R. Connell, Severe accidents in spent fuel pools in support of generic safety, Issue 82, Brookhaven National Lab., Upton, NY (USA), Nuclear Regulatory Commission, Washington, DC (USA). Division of Reactor and Plant Systems, 1987.
Re: Reynolds number factor

$\Delta$ Ps: saturated pressure difference (psi)

$\mathbf{v}$ : kinematic viscosity of the fluid,

Pr: Prandle Number

$\boldsymbol{\beta}$ : Coefficient of volume expansion

$\mathbf{T}_{\infty}$ : Temp. fluid sufficiently
c : condenser
0: initial
I : liquid
nc: natural convection
f: working fluid sat saturation
w: wall

11.E.D. Throm, Beyond design basis accidents in spentfuel poolsdgeneric Issue 82, Nucl. Eng. Des. 126 (1991) 333 to 359.

12.Loula A. Shouman, M. Abd El-Aziz, Adel Alyan "Theoretical Steady-state Forced Flow Boiling Evaporator for Double-tube Thermosyphon (FFDTT)" International Journal of Scientific \& Engineering Research Volume 4, Issue 6, June 2013 ISSN 2229-5518. Atomic Energy Authority, Reactors Department, 13759 Cairo, Egypt

13.P.B Whalley, Boiling Condensation and Gas-Liquid Flow, Department of Engineering Science, University of Oxford, 1989.

14.Heat transfer by Yunus A. Cengel, $2^{\text {nd }}$ eddition,NewYork:McGraw-Hill 2002.

15.S.A. Klein and F.L. Alvardo; EES-Engineering Equation Solver; user's Manual for Microsoft Windows Operating Systems, Version 6.160, F-Chart Software, Madison, WI, 2001

16.D. Reay, R. McGlen, P. Kew, Heat Pipes: Theory, Design and Applications, Butterworth-Heinemann, Oxford, UK, 2013.

17.S.H. Noie, Heat transfer characteristics of a twophase closed thermosyphon, Appl. Therm. Eng. 25 (2005) 495 to 506.

18.A. Alizadehdakhel, M. Rahimi, A.A. Alsairafi, CFD modeling of flow and heat transfer in a thermosyphon, Int. Commun. Heat Mass Transf. 37 (2010) 312 to 318 .

19.P.G. Anjakar, D.R.B. Yarasu, Experimental analysis of condenser length effect on the performance of thermosyphon, Int. J. Emerg. Technol. Adv. Eng. 2 (2012) 494 to 499. 